\title{
Formulation of a nonlinear water distribution problem with water rationing: an optimisation approach
}

\author{
Godfrey Chagwiza ${ }^{1}$
}

Received: 27 October 2015/Accepted: 7 September 2016/Published online: 13 September 2016

(C) Springer International Publishing Switzerland 2016

\begin{abstract}
A mixed-integer nonlinear programming water distribution problem that incorporates water rationing is presented. The city of Bulawayo water distribution problem is implemented and solved using max-min ant system, genetic, tabu search, and simulated annealing algorithms with 100 runs performed for each algorithm. The results show that the city of Bulawayo can save $\$ 3158$ a day. The max-min ant system produced the best optimal costs compared with the other algorithms. The least run time is obtained by implementing the tabu search algorithm. Water lost through hoarding during water-rationing periods contributes significantly to the total operational costs. Statistical analysis of the results obtained by different algorithms shows that the optimal costs obtained by tabu search, and simulated annealing algorithms are insignificantly different. Future research may be directed toward incorporating priority among water users and formulating a hybrid algorithm that uses both the max-min ant system and tabu search algorithms to solve such problems.
\end{abstract}

Keywords Mixed-integer nonlinear programming - Water rationing $\cdot$ Optimisation

Godfrey Chagwiza

chagwizag@gmail.com

1 Department of Applied Mathematics, National University of Science and Technology, P.O. Box AC939, Ascot, Bulawayo, Zimbabwe

\section{Introduction}

Water is a scarce resource and must be managed properly to avoid conflicts. Many water authorities, especially in developing countries, are engaging in water rationing as a management tool to easy the pressure on the scarce resource. During droughts, municipal water restrictions focus on residential users rather than letting prices reflect scarcity of the resource during excess demand. Price-based policy would result in allocatable consequences. Rationing is a system that is being used everywhere in the world where there is water shortages. Outdoor watering restrictions were implemented during 1987-1992 drought in California (Dixon et al. 1996). In Australia, $75 \%$ of the population live in mandatory water restriction communities (Grafton and Ward 2008). Charging high volumetric prices of water during shortages can put a burden to the poor and larger households (Grafton and Ward 2008). According to the World Health Organisation (WHO), the basic amount of water required per day per person is 501 (Madden and Carmichael 2007).

According to the study carried out by Mansur and Olmstead (2007), indoor consumption appears to be affected only by income and family size and outdoor use is price elastic during the wet season and price inelastic in the dry season. Substantial gains were available on price-based approach rather than outdoor water rationing. Another study carried by Hensher et al. (2006) on willingness to pay to avoid drought-induced water restrictions concluded that water consumers are unwilling to pay to avoid lowlevel restrictions at all and higher level of restrictions that are not in place everyday.

On the other hand, water consumers are willing to tolerate high-level restrictions on limited periods in a year as compared with higher water bills. Domestic water 
consumers tend to keep more water than required in containers if a water-rationing schedule is out. The excess water will be replaced by fresh water if allocation is resumed, and this leads to higher water consumption levels than before rationing. This study seeks to optimise water distribution costs during water-rationing periods, so as to avoid or minimise extra water costs that are induced through water hoarding which results in higher water consumption.

The remainder of the paper is arranged as follows. A review of leading metaheuristic algorithms that are used in this study is carried out in "Review of metaheuristics". In "Model formulation", formulation of a mixed-integer nonlinear programming (MINLP) problem is presented. Section "The numerical example" presents implementation and application of the four leading algorithms to the MINLP, and in "Conclusions", conclusions are drawn.

\section{Review of metaheuristics}

Metaheuristics have been used to solve water distribution networks. Metaheuristics were first applied to solve a water distribution system by Dougherty and Marryott (1991). Metaheuristics mimic natural processes and have proved to be relevant in water distribution systems optimisation (Walski 2003; Winston 2004). Brief explanations of the Max-Min Ant System (MMAS), Genetic Algorithm (GA), Tabu Search (TS) and Simulated Annealing (SA) algorithms are presented.

\section{The MMAS algorithm}

The algorithm was introduced by Stutzle and Hoos (2000) as an extension of the Ant Colony Optimisation Dorigo (1992) which is an adaptation of the AS algorithm. The algorithm provides dynamically evolving bounds on the pheromone trail intensities. The probability that edge $(i, j)$ will be selected at decision $i$ is given by

$p_{i j}^{z}(t)=\frac{\tau_{i j}^{\alpha}(t) \times \lambda_{i j}^{\beta}(t)}{\sum_{k \in N_{i}^{z}} \tau_{i k}^{\alpha}(t) \times \lambda_{i k}^{\beta}(t)}, \quad j \in N_{i}^{z}$,

where $N_{i}^{z}$ is the feasible neighbourhood of the ant $z$ and $(i k)$ are edges from $i$. Equation (2) represents pheromone updating.

$\tau_{i j}(t+1)=\rho \times \tau_{i j}(t)+\Delta \tau_{i j}(t)$,

where $p_{i j}(t)$ is the probability of choosing edge $(i, j)$ at time $t, \tau_{i j}(t)$ is the concentration of pheromone related to edge $(i, j)$ at period time $t$, and $\lambda_{i j}$ is the preference of edge $(i, j)$. The parameters $\alpha$ and $\beta$ control the relative importance of pheromone intensity and preference for every ant's decision, respectively. The parameter $\rho$ represents pheromone persistence. The quantity $\Delta \tau_{i j}(t)$ represents the pheromone addition for edge $(i, j)$ and it is a function of solutions found at iteration $t$. Equation (3) is the pheromone addition on edge $(i, j)$ at time $t$.

$\Delta \tau_{i j}(t)=\sum_{l=1}^{m} \Delta \tau_{i j}^{l}(t)$

where $\Delta \tau_{i j}^{l}(t)$ is the pheromone addition laid by the $l$ th ant on the edge $(i, j)$ at the end of iteration, $t$, and $m$ is the number of ants. Successful application of MMAS algorithm to water distribution system has been witnessed (Chagwiza et al. 2014; Zecchin et al. 2003; Afshar 2009b).

\section{The GA algorithm}

The genetic algorithm is an algorithm that mimics natural processes selection and belong to evolutionary algorithms. It uses processes, such as mutation, inheritance, selection, and crossover. Genetic algorithm refers to the model that was introduced by Holland (1975). The genetic algorithm is usually applied to nonlinear problems, and modifications of the genetic algorithm called BASIC were also introduced (Shopova and Vaklieva-Bancheva 2006). Genetic algorithm has been previously applied to water distribution systems in studies, such as that of Afshar (2009a), Wu et al. (2001), and Tolson et al. (2004).

\section{The TS algorithm}

The TS algorithm was first introduced by Glover (1989). The metaheuristic is believed to be the one that guides subordinated heuristics to produce solutions beyond those that are produced by search of local optima (Fanni et al. 2000). The algorithm has been long back applied to nonlinear problems (Glover 1977). It uses local search (neighbourhood) that potential solutions, $x$, to the problem are directed to an improved solution, $x^{\prime}$. The algorithm uses three types of memory, that is, short, intermediate, and long term, and they form the tabu list (Glover 1990b). The tabu list contains solutions that can be changed by the process that is involved when moving from one solution to the other. Full explanation of the TS algorithm can be found in Glover and Laguna (1997) and Glover (1990a, 1993, 1994). The TS algorithm has previously been applied to solve water distribution systems problems (Fanni et al. 2000; Cunha and Riberio 2003; Sung et al. 2007).

\section{The SA algorithm}

Simulated annealing was introduced by Kirkpatrick et al. (1983). It uses a set of controlled cooling operations. The 
algorithm has four basic components, that is, configurations which are the possible problem solutions, move set which is a set of allowable moves to reach the feasible configurations, cost function that measures how good each configuration is, and the cooling schedule. The algorithm has been applied to solve water distribution problems (Dougherty and Marryott 1991; Marryott et al. 1993; Cunha 1999; Tospornsampan et al. 2005, 2007).

\section{Model formulation}

A MINLP problem of a water distribution system that includes water rationing during shortage period is developed in this section. Definitions of variables (var) and parameters (par) are shown in Table 1. Equations (4)-(8) are a sub-problem that is used to find the optimal cost, $C_{j, i}$, of implementation measure $j$ during shortage event $i$. The objective (Eq. (4)) is to minimise costs that are related to implementing a measure to water resource allocation during the times of shortages. Equation (5) ensures that the quantity conserved during shortage should balance with quantities conserved by implementation both short- and long-term measures. Implementation constraints (lower and upper implementation) of each measure, that is, either short or long term are presented by Eqs. (6), (7) and (8) is the sign restriction constraint. The result from this model is implemented in the main model [Eqs. (9)-(15)]

$\operatorname{Min} C_{j, i}=\sum_{\hat{j} \in j, i \in M} C_{\hat{j}, i}\left(U_{\hat{j}, i}+L_{\hat{j}, i}\right) Y_{\hat{j}, i}+\sum_{\tilde{j} \in j, i \in M} C_{\tilde{j}, i}\left(U_{\tilde{j}, i}+L_{\tilde{j}, i}\right) Y_{\tilde{j}, i}$

subject to

$$
\begin{aligned}
& Y_{j, i} \geq Y_{\hat{j}, i}+Y_{\tilde{j}, i}, \quad \forall \hat{j} \in j, \quad \forall \tilde{j} \in j \\
& U_{j, i} \geq U_{\hat{j}, i}+U_{\tilde{j}, i}, \quad \forall \hat{j} \in j, \quad \forall \tilde{j} \in j
\end{aligned}
$$

Table 1 Definitions of model

\begin{tabular}{|c|c|c|}
\hline Name & Definition & Type \\
\hline$B_{i, t}$ & Operational and maintenance costs incurred in shortage event $i$ at time period $t$ & Par \\
\hline$C_{j, i}$ & Cost of implementing conservation measure $j$ in shortage event $i$ & Par \\
\hline$C_{\hat{j}, i}$ & Cost of implementing long-term conservation measure $j$ in shortage event $i$ & Par \\
\hline$C_{\tilde{j}, i}$ & Cost of implementing short-term conservation measure $j$ in shortage event $i$ & Par \\
\hline$D_{i, t}$ & Full-service demand in shortage event $i$ at time $t$ & Par \\
\hline$E_{i, t}$ & Retail price of water for each shortage event $i$ & Par \\
\hline$F_{i, t}$ & Quantity of water available in shortage event $i$ at time $t$ & Var \\
\hline$H_{i, t}$ & Penalty for failing to meet demand & Par \\
\hline$i$ & Index identifying shortage event & - \\
\hline$j$ & Index identifying conservation measure type available $j$ & - \\
\hline$\hat{j}$ & Index identifying long-term measure & - \\
\hline$\tilde{j}$ & Index identifying short-term measure & - \\
\hline$L_{j, i}$ & Lower limit of measure $j$ in event $i$ & Var \\
\hline$L_{\hat{j}, i}$ & Lower limit of long-term measure $j$ in event $i$ & Var \\
\hline$L_{\tilde{j}, i}$ & Lower limit of short-term measure $j$ in event $i$ & Var \\
\hline$M$ & Number of shortage events $i$ & Par \\
\hline$N$ & Number of measure type $j$ & Par \\
\hline$P_{i}$ & Probability of shortage event $i$ occurring & Par \\
\hline$Q_{i, t}$ & Quantity of water lost in shortage event $i$ and period $t$ & Var \\
\hline$R_{i, t}$ & Ration amount for shortage event $i$ at time $t$ & Par \\
\hline$t$ & Index identifying period (time), $t \in T$ & - \\
\hline$U_{j, i}$ & Upper limit of measure $j$ in event $i$ & Var \\
\hline$U_{\hat{j}, i}$ & Upper limit of long-term measure $j$ in event $i$ & Var \\
\hline$U_{\tilde{j}, i}$ & Upper limit of long-term measure $j$ in event $i$ & Var \\
\hline$X_{j, i}$ & Implementation level of measure $j$ in shortage event $i$ & Var \\
\hline$Y_{j, i}$ & Quantity of water conserved in shortage event $i$ by measure $j$ & Var \\
\hline$Y_{\hat{j}, i}$ & Quantity of water conserved in shortage event $i$ by long-term measure & Var \\
\hline$Y_{\tilde{j}, i}$ & Quantity of water conserved in shortage event $i$ by short-term measure & Var \\
\hline$Z$ & Objective function & Par \\
\hline
\end{tabular}
variables 
$L_{j, i} \geq L_{\hat{j}, i}+L_{\tilde{j}, i}, \quad \forall \hat{j} \in j, \forall \tilde{j} \in j$

$Y_{j, i} \geq 0, \quad Y_{\hat{j}, i} \geq 0, \quad Y_{\tilde{j}, i} \geq 0$.

The model is an MINLP problem and the objective is to minimise water distribution costs that are incurred during water-rationing periods. The costs include penalties associated with failure to meet demand, $H_{i, t}$, operational and maintenance, $B_{i, t}$, and costs. Equation (11) shows that the full-service demand minus quantity of water available during shortage should be greater than zero, so as to ensure that there is, indeed, a shortage that requires water rationing. Quantity balance constraint is represented by Eq. (12). Ration amount of water is less than the available quantity of water. Equation (13) represents the implementation of a measure $j$ to the water allocation problem and it is binary: 0 when there is no measure implemented and 1 if a measure is implemented. Equation (15) restricts full-service demand, and available quantity and quantity lost due to water hoarding to be positive

$$
\begin{aligned}
\operatorname{Min} \mathrm{Z}= & P_{i} \sum_{i \in M, t \in T} E_{i, t}\left(Q_{i, t}+F_{i, t}\right)+\sum_{i \in M, t \in T} H_{i, t}\left(D_{i, t}-F_{i, t}\right) \\
& +\sum_{j \in N, i \in M} C_{j, i} X_{j, i} Y_{j, i}+\sum_{i \in N, t \in T} B_{i, t} F_{i, t}
\end{aligned}
$$

subject to

$Y_{j, i} \geq Y_{\hat{j}, i}+Y_{\tilde{j}, i}, \quad \forall \hat{j} \in j, \forall \tilde{j} \in j$

$D_{i, t}-F_{i, t} \geq 0, \quad \forall i \in M, \forall t \in T$

$F_{i, t} \geq R_{i, t}, \quad \forall i \in M, \forall t \in T$

$X_{j, i} \geq 0, \quad \forall j \in N, \forall i \in M$

$X_{j, i} \in[0,1]$

$D_{i, t} \geq 0, \quad F_{i, t} \geq 0, \quad Q_{i, t} \geq 0$

\section{The numerical example}

The city of Bulawayo in Zimbabwe is the second largest in the country and has been affected by water shortages for a long time. The city is supplied by three dams, has seven distribution reservoirs with a capacity of $407,750 \mathrm{~m}^{3}$, and a daily demand of $178,000 \mathrm{~m}^{3}$. The city is hit by successive droughts and characterised by massive water-rationing periods that can lasts up to 4 days in a week in some areas without receiving water supplies. Even if the water catchment areas receive good or adequate rains, there is less to talk about in terms of improvements in uninterrupted water supplies to the water consumers. The city publishes a water-rationing schedule to the residents, but in most cases, it does not stick to it. Residents of the city use large plastic and metal containers to hoard water during water-rationing periods. Water consumers experience massive water rationing during the dry period and the early days into the rainy season (May-November). Computations were executed in the MATLAB environment on a PC with AMD E-300 APU with Radeon ${ }^{\mathrm{TM}} @ 1.30 \mathrm{GHz}$ and $4.00 \mathrm{~GB}$ RAM using the city of Bulawayo water data summarised in Table 2.

The water allocation problem has a total of 9 variables and 27 constraints. A total of 100 runs are performed for each optimisation algorithm. Parameters that are used in the problem are adjusted to direct the solution after every ten instances. The average values of each parameter that produced optimal solution are summarised in Table 3. The results show that the city of Bulawayo can incur costs amounting to $\$ 1842$ per day if the model is implemented. This is against the cost of $\$ 5000$ per day, the city is incurring at the time of this study. The city can save a total of $\$ 3158$ per day if the model is implemented. The costs the city incurs, at the time of the study, are largely due to water that is lost through water hoarding. Water users tend to hoard water when they know that they will have longer water-rationing periods. In most cases, water users tend to replace 'stale' water with fresh water when it is available. The city does not follow the published water-rationing schedule and sometimes supply water earlier than the scheduled water-rationing period, and residents replace stored water with fresh water anticipating longer waterrationing periods.

\section{Analysis of the performance of optimisation algorithms}

To produce better results of the water supply problem, a total of four leading optimisation heuristics in literature are used and these are the MMAS, GA, TS, and SA algorithms. The heuristic parameters that produced best results are shown in Table 3. The minimum and maximum optimal costs and corresponding run times are also shown in Table 3. The results show that the MMAS algorithm produced the best average optimal cost of $\$ 1842$ at an average run time of 3.86 min compared with $\$ 2273, \$ 2378$, and $\$ 2052.4$ achieved by GA, TS, and SA, respectively. The minimum optimal cost obtained by the MMAS algorithm is $\$ 1792$ after 3.61 min of run time, \$2198 for GA after 3.05 min, \$2303 for TS after 1.39 min, and \$1992.4 for SA after $2.03 \mathrm{~min}$. The MMAS algorithm performed better, maybe because of better exploration property of the algorithm as compared with GA, TS, and SA which are inflexible. The TS algorithm produced the worst solution result at $2.69 \mathrm{~min}$ of run time. Although the TS algorithm produced worst 
Table 2 Summary of the city of Bulawayo water data

\begin{tabular}{ll}
\hline Description & Value \\
\hline Retail price $\left(\$ / \mathrm{m}^{3}\right)$ & 1.12 \\
Operational and maintenance costs $\left(\$ / \mathrm{m}^{3} /\right.$ day $)$ & 0.05 \\
Quantity of water available $\left(\mathrm{m}^{3} /\right.$ day $)$ & 100,000 \\
Estimated quantity of water lost through hoarding $\left(\mathrm{m}^{3} /\right.$ day) & 20,000 \\
Estimated penalty for failure to meet demand $(\$ /$ day) & 0.2 \\
Full-service demand $\left(\mathrm{m}^{3} /\right.$ day) & 178,000 \\
Water ration amount $\left(\mathrm{m}^{3} /\right.$ day) & 110,000 \\
Number of long-term measures & 1 \\
Number of short-term measures & 1 \\
Cost of implementing short-term measure $(\$ /$ day) & 0.5 \\
Cost of implementing long-term measure $(\$ /$ day) & 0.4 \\
Lower limit of long-term measure $\left(\mathrm{m}^{3} /\right.$ day) & 30,000 \\
Upper limit of long-term measure $\left(\mathrm{m}^{3} /\right.$ day) & 50,000 \\
Lower limit of short-term measure $\left(\mathrm{m}^{3} /\right.$ day) & 1000 \\
Upper limit of short-term measure $\left(\mathrm{m}^{3} /\right.$ day) & 19,000 \\
Quantity of water conserved by long-term measure $\left(\mathrm{m}^{3} / \mathrm{day}\right)$ & 2000 \\
Quantity of water conserved by short-term measure $\left(\mathrm{m}^{3} /\right.$ day) & 5000 \\
\hline
\end{tabular}

\begin{tabular}{|c|c|c|c|c|c|}
\hline \multirow[t]{2}{*}{ Algorithm } & \multicolumn{3}{|c|}{ Parameter information } & \multirow{2}{*}{$\begin{array}{l}\text { Optimal solution } \$ \\
{[\min , \max ]}\end{array}$} & \multirow{2}{*}{$\begin{array}{l}\text { Run time (min) } \\
{[\min , \max ]}\end{array}$} \\
\hline & Symbol & Definition & Value & & \\
\hline \multirow[t]{3}{*}{ MMAS } & $\alpha$ & Pheromone intensity control & 0.7 & & \\
\hline & $\beta$ & Preference control & 0.5 & & \\
\hline & $\rho$ & Persistence control & 0.98 & $1842[1792,1892]$ & $3.86[3.61,4.11]$ \\
\hline \multirow[t]{5}{*}{ GA } & $p_{m}$ & Mutation & 0.05 & & \\
\hline & $\sigma$ & Mutation step & 0.1 & & \\
\hline & $p_{c}$ & Crossover rate & 0.7 & & \\
\hline & $\mu$ & Population size & 120 & & \\
\hline & $\lambda$ & Offspring size & 75 & $2273[2198,2346]$ & $3.65[3.05,4.22]$ \\
\hline \multirow[t]{2}{*}{$\mathrm{TS}$} & $s$ & Tabu tenure & 1000 & & \\
\hline & $G$ & Termination criteria & 1000 & $2378[2303,2450]$ & $2.69[1.39,3.94]$ \\
\hline \multirow[t]{2}{*}{ SA } & $t_{0}$ & Initial temperature & 120 & & \\
\hline & $T$ & Stopping temperature & 75 & $2052.4[1992.4,2115]$ & $2.78[2.03,3.03]$ \\
\hline Mean & & & & $2136.35[1792,2450]$ & $3.24[1.39,4.22]$ \\
\hline
\end{tabular}

Table 3 Summary of parameter values and results of various optimisation algorithms run times. In general, it is shown that there is a significant $(p=0.000)$ difference between both optimal costs and run times obtained by the different algorithms. A comparison to test the statistical difference within the algorithms is done. Tables 5 and 6 show the results of comparisons of optimal costs and run times within the algorithms, respectively. The average mean optimal costs (\$2136.35) and run time $(3.24 \mathrm{~min})$ are used to find the mean differences. The results in Table 5 show that there is a significant difference on optimal costs obtained by each algorithm as compared with the other algorithms. The run times are significantly different for all the algorithms except those required by SA and TS $(p=0.86)$. 
Table 4 Analysis of variance results of the algorithms implemented
Table 5 Statistical comparison of optimal cost

\begin{tabular}{llllll}
\hline Variable & Sum of squares & Degrees of freedom & Mean square & $F$ & $p$ value \\
\hline Cost & & 3 & & & \\
$\quad$ Between groups & $17,075,747$ & 396 & $5,691,915.66$ & 3894.288 & 0.00 \\
$\quad$ Within groups & 578,796 & 399 & & & \\
$\quad$ Total & $17,654,543.000$ & & & & \\
Time & & 3 & 35.676 & 185.379 & 0.00 \\
$\quad$ Between groups & 107.028 & 396 & 0.192 & & \\
$\quad$ Within groups & 76.210 & 399 & & & \\
$\quad$ Total & 183.238 & & & & \\
\hline
\end{tabular}

\begin{tabular}{|c|c|c|c|c|c|c|c|c|}
\hline \multirow{2}{*}{$\begin{array}{l}\text { Algorithm } \\
i\end{array}$} & \multicolumn{4}{|l|}{$\begin{array}{l}p \text { value } \\
j\end{array}$} & \multicolumn{4}{|c|}{ Mean difference $\$(i-j)$} \\
\hline & MMAS & GA & TS & SA & MMAS & GA & TS & SA \\
\hline MMAS & - & 0.00 & 0.00 & 0.00 & - & $(431)$ & $(538)$ & $(210.4)$ \\
\hline GA & 0.00 & - & 0.00 & 0.00 & 431 & - & $(105)$ & 220.6 \\
\hline TS & 0.00 & 0.00 & - & 0.00 & 536 & 105 & - & 325.6 \\
\hline SA & 0.00 & 0.00 & 0.00 & - & 210.4 & (220.6) & (325.6) & - \\
\hline
\end{tabular}

Table 6 Statistical comparison of run time

\begin{tabular}{|c|c|c|c|c|c|c|c|c|}
\hline \multirow{2}{*}{$\begin{array}{l}\text { Algorithm } \\
i\end{array}$} & \multicolumn{4}{|l|}{$\begin{array}{l}p \text { value } \\
j\end{array}$} & \multicolumn{4}{|c|}{ Mean difference $(i-j)$} \\
\hline & MMAS & GA & TS & SA & MMAS & GA & TS & SA \\
\hline MMAS & - & 0.00 & 0.00 & 0.00 & - & 0.21 & 1.17 & 1.09 \\
\hline GA & 0.00 & - & 0.00 & 0.00 & $(0.21)$ & - & 0.96 & 0.87 \\
\hline TS & 0.00 & 0.00 & - & 0.86 & $(1.17)$ & $(0.96)$ & - & $(0.09)$ \\
\hline SA & 0.00 & 0.00 & 0.86 & - & $(1.09)$ & $(0.87)$ & $(0.09)$ & - \\
\hline
\end{tabular}

\section{Conclusions}

A water distribution problem that incorporates water rationing has been presented as a mixed-integer nonlinear programming problem. The objective of the model is to minimise water distribution costs while incorporating water-rationing-related costs. Four main leading optimisation algorithms, that is, MMAS, GA, SA, and TS, were implemented to solve the problem. The results show that the city of Bulawayo, which is used as an example in this research, can save a significant amount of money if the model is implemented. On the other hand, the MMAS algorithm produced the least optimal cost as compared with the other algorithms. The least run time is achieved by implementing the TS algorithm. It is, therefore, recommended that a hybrid algorithm to solve water distribution problems of the same nature as the one presented in this research be formulated to get best optimal solution.

\section{References}

Afshar M (2009a) Application of a compact genetic algorithm to pipe network optimization problems. Trans A Civil Eng 16(3):264-271

Afshar MH (2009b) Elitist-mutatant ant system versus max-min ant system: application to pipe network optimization problems. Trans A Civil Eng 16(4):286-296

Chagwiza G, Jones BC, Hove-Musekwa SD (2014) Impact of new water sources on the overall water network: an optimisation approach. Int Scholar Res Not 2014:8

Cunha CM, Riberio L (2003) Tabu search algorithms for water network optimization. Eur J Oper Res 157(2004):746-758

Cunha MDC (1999) On solving aquifer management problems with simulated annealing algorithms. Water Resour Manag 13:153-169

Dixon LS, Moore NY, Pint EM (1996) Drought management policies and economic effects in urban areas of california, 1987-1992. RAND, Santa Monica

Dorigo M (1992) Optimization, learning and natural algorithms. $\mathrm{PhD}$ thesis, Politecnico di Milano, Italy

Dougherty D, Marryott R (1991) Optimal groundwater management: 1. Simulated annealing. Water Resour Res 27(10):2493-2508 
Fanni A, Liberatore S, Sechi G, Soro M, Zuddas P (2000) Optimization of water distribution systems by a tabu search metaheuristic. In: Laguna M, Velarde J (eds) Computing tools for modeling, optimization and simulation, operations research/computer science interfaces series, vol 12. Springer, USA, pp 279-298

Glover F (1977) Heuristics for integer programming using surrogate constraints. Decis Sci 8(1):156-166

Glover F (1989) Tabu search-Part I. ORSA J Comput 1(3)

Glover F (1990a) Tabu Search-part II. ORSA J Comput 2(1)

Glover F (1990b) Tabu search: a tutorial. Interfaces 20(4):74-94

Glover F (1993) Tabu search, modern heuristic techniques for combinatorial problems. Blackwell Scientific Publications, Oxford

Glover F (1994) Tabu search fundamentals and uses. University of Colorado, Boulder

Glover F, Laguna M (1997) Tabu search. Kluver Academic Publishers

Grafton RQ, Ward M (2008) Prices versus rationing: Marshallian surplus and mandatory water restrictions. Econ Rec 84:S57-S65

Hensher D, Shore N, Train K (2006) Water supply security and willingness to pay to avoid drought restrictions. Econ Rec 81:566

Holland J (1975) Adaptation in natural and artificial systems. University of Michigan Press, Ann Arbor

Kirkpatrick C, Gelatt D, Vecchi MP (1983) Optimisation by simulated annealing. Science 220(4598):671-680

Madden C, Carmichael A (2007) Every last drop. Random House Australia, Sydney

Mansur ET, Olmstead SM (2007) The value of scarce water: measuring the inefficiency of municipal regulations. NBER Working Paper 13513

Marryott RA, Dougherty DE, Stollar RT (1993) Optimal groundwater management, 2. Application of simulated annealing to a fieldscale contamination site. Water Resour Res 29(4):847-860
Shopova EG, Vaklieva-Bancheva NG (2006) BASIC genetic algorithm for engineering problems solution. Comput Chem Eng 30(8):1293-1309

Stutzle T, Hoos HH (2000) MAX-MIN ant system. Future Gener Comput Syst 16:889-914

Sung Y, Lin M, Lin Y, Liu Y (2007) Tabu search solution of water distribution network optimisation. J Environ Eng Manag 17(3):177-187

Tolson BA, Maier HR, Simpson AR, Lence BJ (2004) Genetic algorithms for reliability based optimisation of water distribution systems. J Water Resour Plan Manag 130(1):63-72

Tospornsampan J, Kita I, Ishii M, Kitamura Y (2005) Optimization of multiple reservoir system using simulated annealing: a case study in the Mae Klong system, Thailand. Paddy Water Environ 3(3):137-147

Tospornsampan J, Kita I, Ishii M, Kitamura Y (2007) Split-pipe design of water distribution network using simulated annealing. Int J Environ Chem Ecol Geol Geophys Eng 1(4):28-38

Walski TM (2003) Advanced water distribution modeling and management. Haestad Press, Waterbury

Winston WL (2004) Operations research: applications and algorithms $\left(4^{\text {th }}\right.$ ED. Thomson-Brooks/ Cole, Belmont

Wu Z, Boulos P, Orr C, Ro J (2001) Using genetic algorithms to rehabilitate distribution systems. J Am Water Works Assoc 93(11):74-85

Zecchin AC, Maier HR, Simpson AR, Roberts AJ, Berrisford MJ, Leornard M (2003) Max-Min ant system applied to water distribution system optimisation. In: Proceedings MODSIM 2003: International Congress on Modelling and Simulation. Townsville, Queensland, Australia, pp 795-800 